\title{
Arthritis, deformities, and runting in C5-deficient mice injected with human rheumatoid arthritis synovium
}

\author{
J. F. S. CROCKER, T. GHOSE, K. ROZEE, J. WOODBURY, AND B. STEVENSON
} From the Departments of Pediatrics, Pathology, Microbiology, and Medicine, Dalhousie University, Halifax, Nova Scotia, Canada

SYNOPSIS The pathogenesis of rheumatoid arthritis might be more easily understood and the efficacy of therapeutic measures might be more accurately assessed if a convenient animal replica of this disease were available for laboratory study. Intraperitoneal injection of homogenates of inflamed synovium taken at operation from patients with rheumatoid arthritis produces inflammatory swelling and deformity in the tail and extremities of a proportion of injected mice from a complement (C5)-deficient inbred strain. Swelling of the paws leads to limping of the affected mice. The lesions are transmissible from generation to generation. The results support the theory of a transmissible agent in the inflamed synovium of rheumatoid arthritis patients.

It has been reported that intraperitoneal injection of synovium from affected joints of rheumatoid arthritis patients produced inflammation in the paws and tails of mice as well as in their non-injected progeny (Warren, Marmor, Liebes, and Hollins, 1969). Similar lesions were later also produced in chicks after inoculation of rheumatoid arthritis synovium homogenate into the air sacs of fertilized eggs and also in rats after ingestion of rheumatoid arthritis synovial tissue (Warren, Marmor, Boak, and Liebes, 1971; Warren, Marmor, Liebes, and Rosenblatt, 1972). We have injected homogenates of human rheumatoid arthritis synovial tissue into a C5-deficient strain of mice and have observed lesions similar to those described by Warren et al. We have also observed runting of growth in some of these mice.

\section{Materials and Methods}

Synovial tissues obtained during surgery from nine patients with active rheumatoid arthritis and five osteoarthritis patients were carefully freed of fat, washed in phosphate-buffered saline $(0.01 \mathrm{M}, \mathrm{pH}$ $7 \cdot 1$ ), homogenized, and stored at $-70^{\circ} \mathrm{C}$. C5-deficient SWR mice were originally obtained from the Jackson Memorial Laboratory (Bar Harbour, Maine). They were subsequently maintained in this labora-

Received for publication 20 September 1973. tory by brother-sister mating. The complemen deficiency of these mice was confirmed using thes haemolytic test described by Cinader, Dubiski, an Wardlaw (1954). Aseptic techniques were followed during the collection, preparation, and injection of synovial tissue.

Pairs of adult male and female SWR mice of $20-22 \mathrm{~g}$ were injected intraperitoneally with $13 \mathrm{mg}$ wet weight of synovial tissue homogenate and then allowed to mate. The members of the resulting $F_{1}$ progeny were injected intraperitoneally within 24 hours of birth with $9 \mathrm{mg}$ of synovial tissue homogenate (human). When 16 weeks old, members of this $F_{1}$ progeny were grouped in pairs of male and female and after intraperitoneal injection of $47.6 \mathrm{mg}$ of synovial homogenate they were allowed to brother-sister mate. Each member of the newborn $F_{2}$ progeny received $4.76 \mathrm{mg}$ of synovial homogenate intraperitoneally within 24 hours of birth. At maturity the members of the $F_{2}$ progeny were of also grouped in male-female pairs, injected with $N$ $47.6 \mathrm{mg}$ of synovial homogenate/mouse and then were allowed to mate. The newborn members of the $\mathrm{F}_{3}$ generation similarly received intraperitoneal injection of synovial homogenate $(4.76 \mathrm{mg} / \mathrm{mouse})$ within 24 hours of birth, after which all injections of synovial homogenate were stopped. At maturity, the mice were separated in male-female pairs and were mated. Resulting offspring were not injected (see table). 


\begin{tabular}{|c|c|c|c|c|}
\hline \multirow[t]{2}{*}{ Generation } & \multirow[t]{2}{*}{ Number } & \multicolumn{3}{|l|}{ Abnormalities } \\
\hline & & Swollen Tail & Swollen Feet & Runts \\
\hline $\begin{array}{l}F_{2} \\
F_{3} \\
F_{4}\end{array}$ & $\begin{array}{l}28 \\
72 \\
31\end{array}$ & $\begin{array}{l}3 \\
1^{1} \\
1\end{array}$ & $\begin{array}{l}5 \\
7 \\
5\end{array}$ & $\begin{array}{l}0 \\
6 \\
0\end{array}$ \\
\hline
\end{tabular}

Table Results of injection of synovium from rheumatoid arthritis patients

${ }^{1}$ Offspring which were not injected.

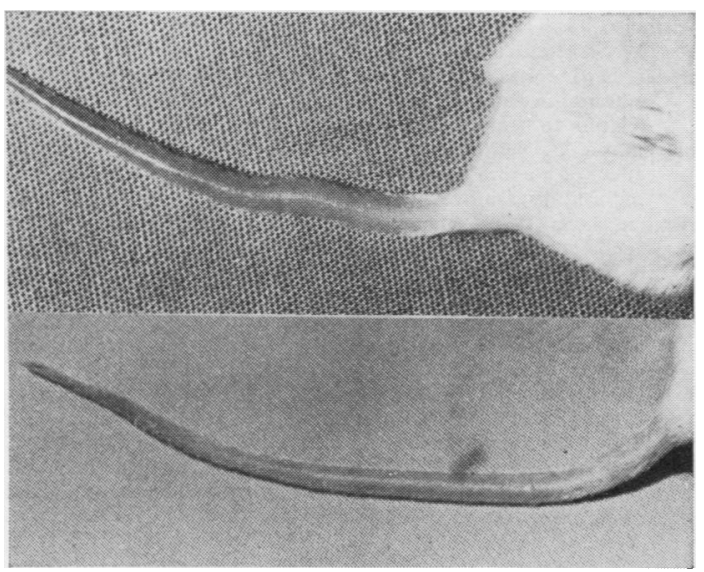

Fig 1 A rheumatoid synovium-injected $F_{2} S W R$ mouse with inflamed and swollen tail. The tail of an uninjected SWR mouse of approximately the same age is shown below for comparison.

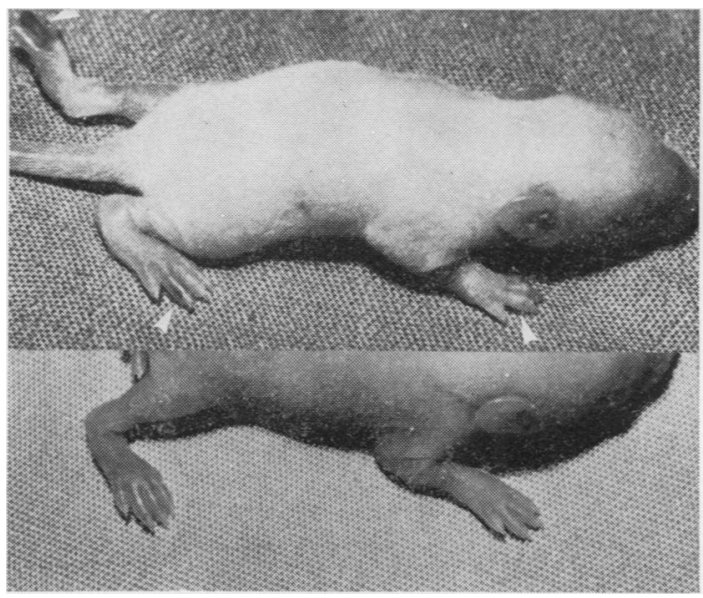

Fig 2 Red and swollen digits (marked with arrows) in the paws of a rheumatoid synovium-injected 2-week-old $F_{1} S W R$ mouse. The limbs of an uninjected $S W R$ mouse of the same age are shown below for comparison.

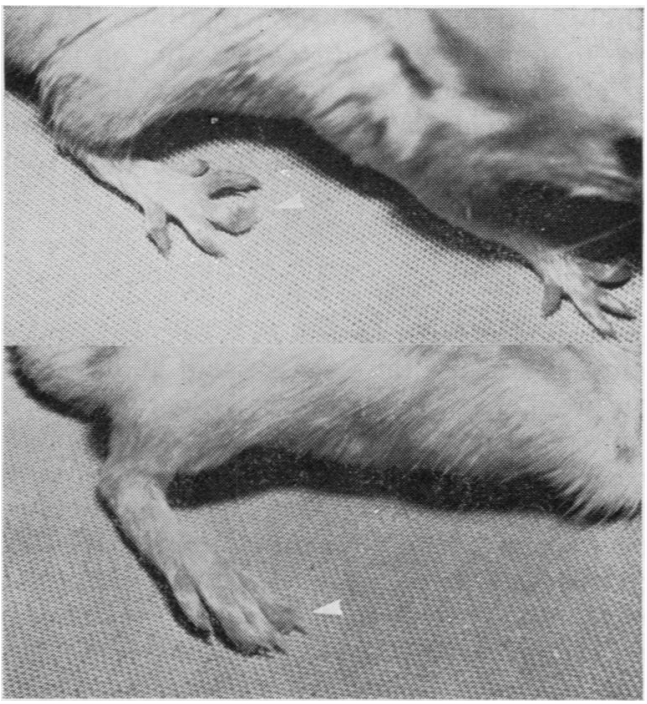

Fig 3 Crooked and terminally swollen digits after recurrent attacks of inflammation in a rheumatoid synovium/injected $F_{2}$, 9-month-old SWR mouse. The digits of the corresponding limb of an uninjected mouse of approximately the same age are shown below for comparison.

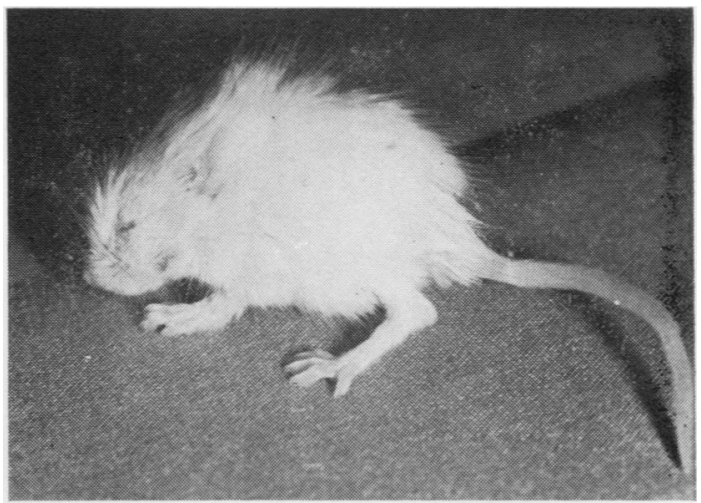

Fig 4 A 12-week-old rheumatoid synovium-injected $F_{3}, S W R$ mouse showing 'runting'. Note the emaciation and ruffled fur.

\section{Results}

The type of abnormality and its observed incidence in the different generations of SWR mice is presented in the table. Swelling and inflammation of tails (fig 1) and paws (fig 2) were always transient. However, recurrent episodes of inflammation ultimately led to persistent deformities of the tails and limbs (fig 3). Usually the affected mice had lesions in all the 
four limbs. Runting (fig 4) was temporary. 'Catchup' growth took place about 16 weeks after birth. No similar abnormalities were noted in several generations of uninjected SWR mice or SWR mice similarly injected with homogenates of synovium from osteoarthritis patients.

\section{Discussion}

The indication of joint lesions in C5-deficient mice is interesting because this suggests that joint lesions can be produced without the participation of the classical complement cascade. This may be similar to those human conditions where arthritis similar to rheumatoid arthritis is found in agammaglobulinaemic and complement-deficient patients (Christian, 1971; Lawrence, 1970).

Complement depletion by cobra venom in Freund's adjuvant arthritis in rats delays the onset of arthritis in these animals (Kourounakis, Nelson, and Kupusta, 1973). Whether the relatively low numbers of animals having arthritis in our work compared with the Warren model is due to the complement deficiency, we are unable to state at present. Though it confirms the observation of Warren et al, our study has not yet elucidated either the aetiology or the nature of arthritis in these experimental models. Similarly the cause of runting and delayed skeletal development in these mice has yet to be explained.

We wish to acknowledge the participation of the staff of the Dalhousie Rheumatic Disease Unit and the assistance of the orthopaedic surgeons of the teaching hospitals of Dalhousie University in obtaining synovium.

\section{References}

Christian, C. L. (1971). Immunological Diseases, 2nd edit., edited by M. Samter, p. 1024. Little, Brown, Boston.

Cinader, B., Dubiski, S., and Wardlaw, A. C. (1964). Distribution, inheritance, and properties of an antigen, MUB ${ }^{1}$, and its relation to hemoly tic complement. J. exp. Med., 120, 897-924.

Kourounakis, L., Nelson, R. A., Jr, and Kupusta, M. A. (1973). The effect of a cobra venom factor on complement and adjuvantinduced disease in rats. Arthr. and Rheum., 16, 71-76.

Lawrence, J. S. (1970). Rheumatic diseases in hypogammaglobulinaemia patients and their relatives. In Hypogammaglobulinaemia in the United Kingdom (Medical Research Council, SRS 310), pp. 35-44. HMSO, London.

Warren, S. L., Marmor, L., Boak, R., and Liebes, D. M. (1971) Transmission of an active agent from rheumatoid arthritis synovial tissues to chicks. Arch. intern. Med., 128, 619-622.

Warren, S. L., Marmor, L., Liebes, D. M., and Hollins, R. L. (1969). Congenital transmission in mice of an active agent from human rheumatoid arthritis. Nature (Lond.), 223, 646-647.

Warren, S. L., Marmor, L., Liebes, D. M., and Rosenblatt, H. (1972). An active agent from rheumatoid arthritis synoviक tissue. Arch. intern. Med., 130, 899-903. 